\title{
Femoral corrective osteotomy associated with trochlear prosthetics and tibial tuberosity transposition with a tool for treatment of canine patellar dislocation
}

\author{
Osteotomia corretiva de fêmur associada à prótese troclear do \\ joelho e transposição da tuberosidade tibial por dispositivo para tratamento \\ da luxação de patela canina
}

\author{
Solimar Dutra da Silveira ${ }^{1 *}\left(\mathbb{D}\right.$, Camila Francisca Batschke ${ }^{1}$ (D) , Samara Koloda Cristino Malta ${ }^{1}(\mathbb{D}$,

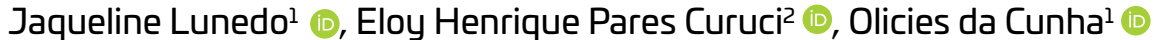

\begin{abstract}
Patellar dislocation is one of the main osteoarticular diseases described in the surgical routine of pet animals, the treatment of which differs according to the degree of dislocation based on the clinical changes presented by each patient. The present report aims to describe the association of the femoral corrective osteotomy technique, total trochlear replacement of the knee by prosthetics, and tibial tuberosity transposition with a tool for correction of grade IV patellar dislocation in a 1.5-year-old German Spitz dog with femoral varus deviation and external tibial torsion. The treatment allowed the correction of femoral bone deformation, realignment of the quadriceps extensor mechanism, and permanent maintenance of the patella on the prosthetic trochlear sulcus with early functional return of the limb, absence of pain, and lameness.
\end{abstract}

KEYWORDS: Knee arthroplasty; dog; angular deviation; bone deformation; femoral varus.

\begin{abstract}
RESUMO: A luxação de patela é uma das principais enfermidades osteoarticulares descrita na rotina cirúrgica de animais de companhia, cujo tratamento difere de acordo com a graduação da luxação baseando-se nas alterações clínicas apresentadas por cada paciente. O presente relato tem como objetivo descrever a associação da técnica de osteotomia corretiva femoral, substituição troclear total do joelho por prótese e transposição da tuberosidade tibial com dispositivo para correção de luxação de patela grau IV em uma canina da raça Spitz Alemão de 1,5 anos com desvio femoral varus e torção externa da tíbia. O tratamento permitiu a correção da deformação óssea femoral, realinhamento do mecanismo extensor do quadríceps e manutenção permanente da patela sobre o sulco troclear protético com retorno funcional precoce do membro, ausência de dor e claudicação.
\end{abstract}

PALAVRAS-CHAVE: Artroplastia de joelho; cão; desvio angular; deformação óssea; varus femoral.

\section{INTRODUCTION}

Femorotibiopatellar disorders are commonly related to lameness and degenerative joint disease (DJD) in pet animals (SINGLETON, 1969). Patellar dislocation (PD) is one of the main joint diseases involved in this condition, affecting predominantly small dogs and occasionally cats (DeCAMP et al., 2015).

$\mathrm{PD}$ can be classified as congenital or traumatic, with lateral, medial or bidirectional positional deviation (SCHULZ, 2014). It is believed that about $75 \%$ of the cases described in dogs correspond to congenital medial dislocation. Among these, approximately 20 to $25 \%$ presented bilateral involvement (DeCAMP et al., 2015). In addition, the disease can present four levels of gradation (I, II, III, and IV), based on the osteoarticular changes developed individually by each patient (SINGLETON, 1969).

Etiologically, the pathophysiology of congenital PD is not completely understood. However, other musculoskeletal changes are usually associated with the disease, such as medial displacement of the quadriceps extensor mechanism, lateral or medial torsion of the distal femur, femoral epiphyseal dysplasia, internal rotational instability, external knee joint, or tibial varus or valgus deformity (DeCAMP et al., 2015; KOWALESKI; BOUDRIEAU; POZZI, 2012; SCHULZ, 2014).

The clinical signs of the disease vary according to the degree of dislocation and its concomitant changes, which 
include from asymptomatic patients to the presence of intermittent or continuous claudication with pain, followed by a reluctance to perform conventional exercises. This condition may progress to joint dysfunction and functional inability of the affected limb (BOSIO et al., 2017; O'NEILL et al., 2016; REZENDE et al., 2016).

The diagnosis is based on the patient's history, detailed orthopedic evaluation and radiographic examination, determining the degree of dislocation, the presence of associated angular deformities, and the resulting osteoarticular involvement in the DJD (DeCAMP et al., 2015; SCHULZ, 2014).

Treatment differs according to the degree of dislocation based on pre-existing clinical changes for each animal (SCHULZ, 2014). Grade I dogs, those with mild and intermittent claudication with no potential for disease progression, are usually treated conservatively through weight control, physical rehabilitation exercises, and in rare cases administration of non-steroidal anti-inflammatory drugs and analgesics (BOSIO et al., 2017; KOWALESKI; BOUDRIEAU; POZZI, 2012). For patients with grade II, III, and IV patellar dislocation whose disease is more evident, the recommended therapy includes the association of surgical techniques that allow the reconstruction of soft and bone tissues in order to reposition the dislocated patella in its trochlear groove, stabilizing the quadriceps extensor mechanism (DeCAMP et al., 2015; PÉREZ and LAFUENTE, 2014).

In view of the wide variety of surgical techniques described for the treatment of patellar dislocation, the aim of this report was to describe a case of canine patellar dislocation grade IV. The treatment for this condition consisted in the association of three different surgical approaches: corrective femoral osteotomy, total trochlear replacement of the knee by prosthetics (Patellar Groove Replacement - PGR) and Tibial Tuberosity Transposition with a Tool technique (TTTT).

\section{CASE REPORT}

A 1 year and 5 months old German Spitz dog with a body mass of $3.5 \mathrm{~kg}$ was seen at a clinic specialized in Veterinary Orthopedics, with a main complaint of functional inability of the left pelvic limb that started about a year ago.

During the Orthopedic evaluation, the presence medial patellar dislocation grade IV was found with significant varus rotational deviation of the left femur, besides the absence of support of the affected limb during ambulation. The patient was referred for a simple radiographic examination (Figure 1-A) and a computerized tomography (CT) was then performed (Figure 1-B). The image tests showed medial lateralization of the patella, tearing of the trochlear sulcus, femoral varus deviation of approximately 13.8 degrees, 15 -degree external tibial torsion, besides the presence of osteophytes and enteseophytes, indicating the onset of degenerative joint disease (DJD).

Due to the alterations observed, surgical treatment was carried out by the association of three different techniques: corrective femoral osteotomy, total trochlear replacement of the knee with prosthetics, and TTTT.

The blood test, renal (urea and creatinine) and hepatic proofs (alkaline phosphatase, alanine aminotransferase, aspartate aminotransferase, total proteins and albumin), electrocardiogram, and echocardiography tests were within the normal range. The patient was premedicated with methadone $(0.2$ $\mathrm{mg} / \mathrm{kg}$ ) and dexmedetomidine $(5 \mathrm{mcg} / \mathrm{kg}$ ), followed by an anesthetic induction with propofol $(4 \mathrm{mg} / \mathrm{kg})$ and maintenance with isoflurane in a semi-open inhalation circuit coupled with $100 \%$ oxygen. A prophylactic antibiotic therapy with cephalothin $(30 \mathrm{mg} / \mathrm{kg})$ was started prior to the anesthetic induction, followed by reapplications every 90 minutes during the surgery.

The left pelvic limb was prepared aseptically, following a central approach from the diaphyseal region of the femur to the most distal lateral portion of the tibial crest. Then, with the center of rotation of the femoral angulation (CORA) predetermined by the tomographic evaluation, a closed wedge osteotomy of approximately $2.59 \mathrm{~mm}$ was performed at the distal bone end with the aid of a sagittal saw. After resection of the fragment, the femur was aligned and fixed with two bone plates inserted into the lateral and medial planes $\left(\mathrm{V} 1805^{\circledR}\right.$ and $\mathrm{V} 1810^{\circledast}$ - Fixin Intrauma, Italy).

Then, by means of a medial parapatellar arthrotomy, the meniscus was inspected, revealing no alterations. With the patella medially deviated, a total trochlear osteotomy was performed, starting at the level of the tendon of the long digital extensor muscle to the proximal end of the trochlea. The choice of the prosthetics was made through preoperative planning and direct visualization during surgery, following the
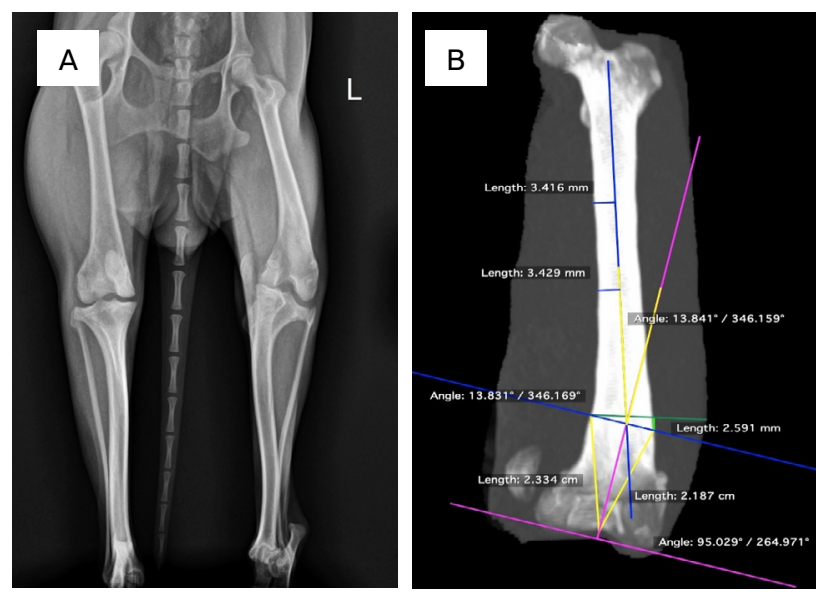

Source: The author, 2020.

Figure 1. Preoperative radiographic and tomographic evaluation. A) Radiographic image in ventro-dorsal view of the coxofemoral and bilateral femorotibiopatellar joints, showing varus-type femoral deviation, medially deviated patella and external tibial torsion. B) Femoral computerized tomographic image in sagittal plane showing the center of rotation of the angulation (CORA) (red arrow) during corrective osteotomy planning. 
principles that the edges of the titanium base presented the same dimensions of the fragment removed by the trochlear osteotomy, as recommended by Dokic et al. (2015).

Next, with the aid of a sagittal saw, small grooves were made on the exposed bone, followed by the fixation of the Number 2 Patellar Prosthetics (Patellar Groove Replacement ${ }^{\circ}$ - Kyon Vet, Switzerland) with stabilization of the base plate using four $1.5 \mathrm{~mm}$ cortical titanium screws and insertion of the joint component by fitting and direct compression with a Teflon Bone Mallet (Figure 2).

After the replacement of the trochlea was completed, the patella was moved to the new prosthetic groove, still showing slight instability during knee flexion and extension due to the external tibial torsion of approximately 15 degrees.

Thus, in order to correct the torsional deformity, partial osteotomy of the tibial crest was performed, maintaining a width of $30 \%$ of the tuberosity in relation to the sagittal bone plane, an extension of $80 \%$ to the medial plane, and $60 \%$ to the lateral plane, keeping its distal portion intact. Then, the TTTT technique was implemented by inserting two $1.5 \mathrm{~mm}$ Steinmann pins in the sagittal plane of the tibia, with a craniocaudal orientation, with an angle of approximately 70 degrees.

Subsequently, a threaded bar was connected horizontally to the pins using two ball joints, parallel to the frontal plane of the osteotomy. With the aid of two nuts, the central flap of the device was gradually slid, following the principles of retraction of $0.7 \mathrm{~mm}$ per minute (equivalent to a complete turn), as described by Petazzoni (2015). When adequate patellar alignment was observed during the movements of flexion, extension, and internal and external articular rotation, a 1.5 $\mathrm{mm}$ Steinmann pin was inserted between the internal and external edge of the osteotomized tibial cortex, at the level of the patellar-tendon insertion, in order to ensure stabilization of the highlighted segment until complete bone healing.

Finally, the surgical wound was sutured in two planes, including subcutaneous tissue in a cushion pattern using 4-0

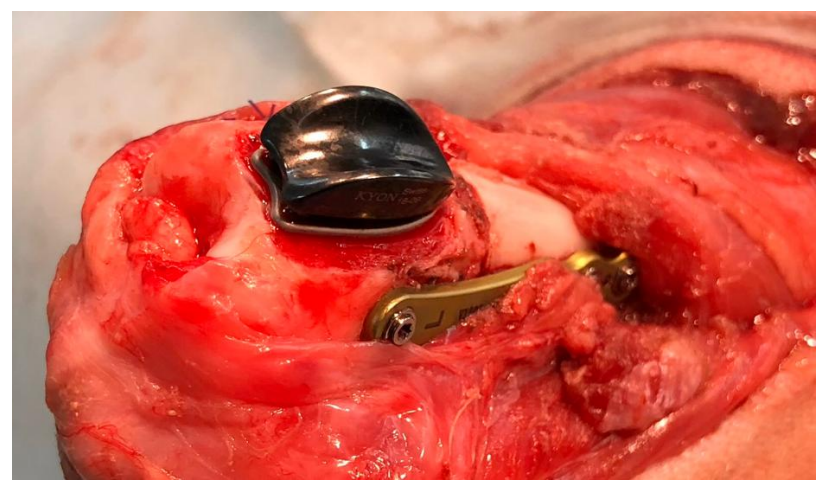

Source: The author, 2020.

Figure 2. Technique of total trochlear replacement by prosthetics (PGR). Final aspect of the implant after fixation of the base and joint components. The presence of the bone plate used for stabilization after corrective femoral osteotomy is observed at the medial femoral plane. polydioxanone thread and dermorography in a simple interrupted pattern with 4-0 mononylon. After 12 hours of the procedure, the patient was discharged with a prescription of antibiotic therapy, analgesia, and guidelines related to surgical wound care. Reassessments were initially carried out with an interval of 14 days, showing complete cutaneous healing and walk without claudication and, after 30,120 , and 180 days postoperatively, using the limb without any restriction, associated with complete bone consolidation, and absence of any signs of instability of the implants by radiographic evaluation (Figure 3).

\section{DISCUSSION}

Patellar dislocation is a disease commonly diagnosed in the surgical routine of pets, affecting mainly small canine breeds such as Toy Poodle, German Spitz, Yorkshire Terrier, and Pinscher (BOUND et al., 2009; O'NEILL et al., 2016; SOUZA et al., 2010). Schulz (2014) described PD as a disease without a sexual predisposition, although recent studies show a higher prevalence in females (BOSIO et al., 2017; O'NEILL et al., 2016). The present case presents a consistent review, since the animal described here is a female, canine, of the German Spitz breed.

According to DeCamp et al. (2015), approximately $75 \%$ of PD cases are related to medial and congenital dislocation, corroborating the findings of the present report, in which the patient had medial patellar deviation and a history of claudication that started at five months old.

In 1969, Singleton adapted a classification for pictures of patellar dislocation, assigning four different degrees for this illness (I, II, III, and IV) based on the clinical changes presented by each patient. In the present case, the signs evidenced during the physical examination confirmed a grade IV condition, since the patient had total absence of support from the
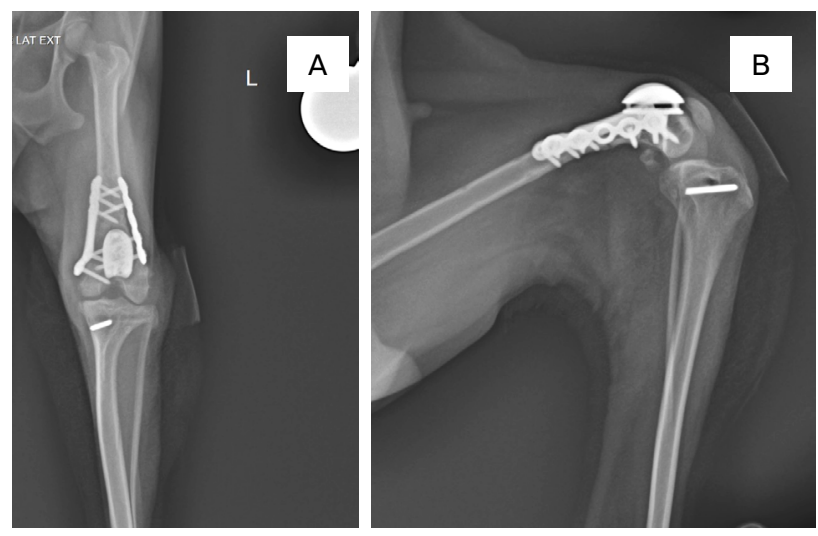

Source: The author, 2020.

Figure 3. Radiographic evaluation 30 days postoperatively. A) Craniocaudal and mediolateral (B) projection of the femur and left tibia showing bone plates inserted into the lateral and medial planes after correction of the femoral varus, knee trochlear prosthetics, and Steinmann pin used in the technique of tibial tuberosity transposition with a tool. 
chronic left pelvic limb, the patella was located medially and permanently ectopic, and the femur presented with a varus of approximately 13.8 degrees. In addition, no trochlear sulcus in the tomographic and trans-surgical evaluations.

Regarding the diagnosis, the history associated with the thorough orthopedic examination is decisive for the confirmation of PD (SCHULZ, 2014). After gait assessment, femorotibiopatellar joint should be inspected in order to locate the patellar dislocation, checking for the presence of deformities and bone rotations, crackles, and range of motion (DeCAMP et al., 2015). Marino and Loughin (2010) mentioned the use of radiographic examination to identify patellar dislocation grades III and IV, in addition to determining bone deformities and changes indicative of DJD. In the present study, the diagnostic method adopted consisted in the physical assessment associated with radiography and computerized tomography, which enabled the measurement of the femoral and tibial CORA; verification of the femoral varus and the absence of the trochlear sulcus; patellar dimensions; alignment of the tibial crest; and preoperative planning of the different techniques adopted.

As for the treatment, it must be based on the specific abnormalities of each case, targeting the realignment of the extensor mechanism of the quadriceps femoris and the patella in the trochlear sulcus; often requiring the combination of different corrective techniques (DeCAMP et al., 2015; KOWALESKI; BOUDRIEAU; POZZI, 2012; SCHULZ, 2014). Among the surgical options, numerous procedures are described in the literature, such as trocleoplasty, tibial tuberosity transposition (TTT), tibial tuberosity transposition with a tool (TTTT), corrective osteotomy, and total trochlear replacement by prosthetics (PGR) (DOKIC et al., 2015; KIM et al., 2017; PETAZZONI, 2015).

Currently, studies associate the excessive conformation of the femoral varus with the pathogenesis of PD in dogs (HARASEN, 2006; O'NEILL et al., 2016; PÉREZ and LAFUENTE, 2014). The femoral corrective osteotomy technique has been recommended as part of the surgical treatment of the disease associated with angular deviations (BROWER et al., 2017), supporting the planning and treatment of the case reported here.

The patient reported in this study had a distal femoral varus deviation of approximately 13.8 degrees, whose bone deformity was corrected by the wedge osteotomy technique, followed by segment fixation using a bone plate system, as described by BROWER et al. (2017). The choice of this technique was based on the degree of deviation identified by radiographic and tomographic examination, together with the high potential for reluxation after traditional approaches in dogs with excessive femoral varus, as described by Arthurs and LangleyHobbs (2006). Regarding bone fixation, we opted for the use of two plates placed on the lateral and medial femoral plane, since after ostectomy little distal bone remained, allowing the insertion of only two screws into the segment. As a result, the inclusion of two implants allowed the segment fixation by four screws, ensuring additional and safe stabilization of the femur, as described by Kim et al. (2016).

Patients with anatomical deformities tend to present displacement of the quadriceps extensor muscles and consequent patellar dislocation. Thus, the absence of pressure from the dislocated patella over the trochlear sulcus is related to insufficient depth or even absence of this structure (DeCAMP et al., 2015; KOWALESKI; BOUDRIEAU; POZZI, 2012; SCHULZ, 2014). The present report showed the absence of a trochlear groove by tomographic evaluation, associated with the presence of periarticular osteophytes and enteseophytes. These changes were correlated with joint incongruence secondary to femoral deformity and chronic patellar dislocation, observed in the patient since she was 5 months old. As a result, we opted for total trochlear replacement with prosthetics (PGR) in order to guarantee a greater joint surface and better alignment of the femoral extensor mechanism, following the principles of the technique described by Dokic et al. (2015).

In addition, the aforementioned authors (DOKIC et al., 2015) associated trochanteric replacement with rapid postoperative recovery, when compared to trochleoplasty, since the conformation of the prosthetics provides a low-friction surface, groove with high and regular edges, allowing smooth sliding of the patella with less damage to soft tissues and joint inflammation.

In cases where the tibial tuberosity is deviated and contributes to subluxation or patellar dislocation, surgical transposition of the tibial crest is recommended as an additional method of knee arthroplasty (PETAZZONI, 2015). Since the patient in the present report had an external tibial torsion of approximately 15 degrees, TTTT was chosen, which guaranteed greater stability to the patellar tendon and the extensor mechanism of the femoral quadriceps in relation to the new joint component.

After conventional surgical treatment (trochleoplasty and tibial tuberosity transposition), up to $50 \%$ of the cases of PD exhibited some degree of recurrence (SCHULZ, 2014). Nevertheless, regarding the techniques used in the present report, there are few published data presenting the percentages of postoperative recurrence. Thus, the patient in the present study was reevaluated at $14,30,120$, and 180 days postoperatively, with an excellent general condition, complete support of the operated limb, walking without claudication, and absence of signs of instability of the bone implants by radiographic evaluation.

\section{CONCLUSION}

In view of the changes described in the present case, the association of corrective femoral osteotomy, total trochlear replacement of the knee, and tibial tuberosity transposition with a tool presented adequate therapeutic results. They allowed the correction of angular deviation, realignment of the extensor mechanism of the femoral quadriceps, and permanent maintenance of the patella over the prosthetic trochlear sulcus, with an early functional return of the limb and absence of pain and lameness during the evaluated postoperative period. 


\section{REFERENCES}

ARTHURS, G. I.; LANGLEY-HOBBS, S. J. Complications associated with corrective surgery for patellar luxation in 109 dogs. Veterinary Surgery, v. 35, n. 6, p. 559-566, 2006.

BOSIO, F. et al. Prevalence, treatment and outcome of patellar luxation in dogs in Italy. A retrospective multicentric study (2009-2014). Veterinary and Comparative Orthopaedics and Traumatology, v. 30, n.5, p. 364-370, 2017.

BOUND, N. et al. The prevalence of canine patellar luxation in three centres. Clinical features and radiographic evidence of limb deviation. Veterinary and Comparative Orthopaedics and Traumatology, v. 22, n. 01, p. 32-37, 2009.

BROWER, B. E. et al. Distal femoral lateral closing wedge osteotomy as a component of comprehensive treatment of medial patellar luxation and distal femoral varus in dogs. Veterinary and Comparative Orthopaedics and Traumatology, v. 30, n. 01, p. 20-27, 2017.

DeCAMP, C. E. et al. The Stifle Joint. Brinker, Piermattei and Flo's handbook of small animal orthopedics and fracture repair. 5. ed. Missouri: Elsevier, 2015. cap. 18, p. 597-669.

DOKIC, Z. et al. Patellar groove replacement in patellar luxation with severe femoro-patellar osteoarthritis. Veterinary and Comparative Orthopaedics and Traumatology, v. 28, n. 02, p. 124-130, 2015.

HARASEN, G. Patellar luxation: Pathogenesis and surgical correction. The Canadian Veterinary Journal, v. 47, n. 10, p. $1037,2006$.

KIM, Y. et al. Bilateral Patellar Groove Replacement in a Dog with latrogenic Trochlear Groove Damage. Journal of Veterinary Clinics, v. 33, n. 5, p. 295-299, 2016.
KOWALESKI, M. P.; BOUDRIEAU, R. J.; POZZI, A. Stifle Joint. In: TOBIAS, K. M.; JOHNSTON, S. A. Veterinary surgery small animal. 1. ed. Missouri: Elsevier, 2012. cap. 62, p. 906-998.

MARINO, D. J.; LOUGHIN, C. A. Diagnostic imaging of the canine stifle: a review. Veterinary Surgery, v. 39, n. 3, p. 284-295, 2010.

O'NEILL D. G. et al. The epidemiology of patellar luxation in dogs attending primary-care veterinary practices in England. Canine Genetics and Epidemiology, v. 3, n. 1, p. 4, 2016.

PÉREZ, P.; LAFUENTE, P. Management of medial patellar luxation in dogs: what you need to know. Veterinary Ireland Journal, v. 4, n. 12, p. 634-640, 2014.

PETAZZONI, M. Tibial Tuberosity Transposition Tool TTTT ${ }^{\circledR}$ and Technique Manual. 1. ed. Milão, Itália: Massimo Petazzoni Books, 2015.65 p.

REZENDE, C. M. F. et al. Patellar luxation in small animals. Canine Medicine: Recent Topics and Advanced Research. London: InTEC, p. 159-178, 2016.

SCHULZ, K. S. Luxação Patelar Medial. In: FOSSUM, T. W. Afecções Articulares. Cirurgia de pequenos animais. 4. ed. Rio de Janeiro: Elsevier, 2014. cap. 34, p. 1353-1360.

SINGLETON, W. B. The surgical correction of stifle deformities in the dog. Journal of Small Animal Practice, v. 10, n. 2, p. 59-69, 1969.

SOUZA, M. M. D. et al. Estudo retrospectivo de cães com luxação patelar medial tratados cirurgicamente. Ciência Rural, v.40, n.6, p.1341-1346, 2010. 